\title{
Música e harmonia: origens da escala diatônica*
}

\author{
Fernando A. R. Sandroni ${ }^{1}$
}

Federação das Indústrias do Estado do Rio de Janeiro

\begin{abstract}
A relação primeira entre as palavras música e harmonia é pesquisada neste trabalho e chega às origens da escala diatônica na forma em que esta foi criada na Grécia Antiga. As evidências historicamente documentadas são baseadas em textos de vários autores da antiguidade, notadamente Filolau de Crotona, Arquitas de Tarento, Nicômaco de Gerasa e Platão. Filolau e Arquitas foram os primeiros filósofos a escrever sobre os ensinamentos de Pitágoras, a quem é atribuída a construção da escala diatônica, sendo, portanto, fontes de grande autoridade. A Platão se devem os mais elevados desenvolvimentos do pensamento pitagórico, aqui extraídos do trecho do diálogo Timeu, que descreve a criação da alma do universo, e aos quais é creditada grande parte da força que manteve intacta a escala diatônica pitagórica na música por mais de 2000 anos.
\end{abstract}

Palavras chave: Música - Harmonia - Pitágoras - Platão
In this paper a research on the primary relation between the words music and harmony is conducted, leading to the origins of the diatonic scale as it was originally created in Ancient Greece. Historically documented evidences are based in texts of several authors of Antiquity, notably Philolaus of Croton, Archytas of Tarentum, Nicomachus of Gerasa and Plato. Philolaus and Archytas were the first philosophers to write about Pythagoras' teachings, to whom the construction of the diatonic scale is attributed; they are thus sources of great authority. To Plato are due the most elevated developments of the pythagoric thought, here extracted from the part of the Timaeus dialogue describing the creation of the universes's soul. To them a great part is credited of the force which kept the pythagorical diatonic scale intact in music for over 2000 years.

Keywords: Music - Harmony - Pythagoras - Plato

\section{Introdução}

$\mathrm{Q}$ ue relação existe entre as palavras música e harmonia? Hoje talvez tenhamos dificuldade em definir uma relação simples. Ao tentar, provavelmente ficaríamos perdidos na explicação de conceitos muito amplos.

\footnotetext{
* Music and harmony: origins of the diatonic scale

${ }^{1}$ Engenheiro pela PUC do Rio de Janeiro. Maitre ès Sciences pela ENSA-Paris 1968. Trabalhou na PETROBRAS e foi diretor de engenharia da COPENE, (hoje BRASKEM) empresa que criou o Polo Petroquímico de Camaçari. Premiado em 2001 pelo MDIC, na comemoração dos 50 anos do CNPq. Faz parte da Academia Nacional de Engenharia, do Conselho de Desenvolvimento da PUC-RJ e do Conselho Consultivo da ABIFINA. Ex-membro do Conselho de Administração do Instituto de Matemática Pura e Aplicada (RJ), e do Conselho Nacional de Ciência e Tecnologia. Preside o Conselho de Tecnologia da FIRJAN. Estudou piano, teoria musical e harmonia no Conservatório Brasileiro de Música. Teve composições gravadas em caráter particular pelo Quinteto Villa Lobos. É pesquisador da música popular brasileira e fundou o grupo musical Lira Carioca (fersan@uninet.com.br).
} 


\section{HUMANAS}

As duas palavras provem do grego. "Mousiké" significava originariamente o conjunto de todas as artes patrocinadas pelas Musas e "harmonia" designava uma união perfeita. $\mathrm{Na}$ arte da construção naval "harmonia" era o nome dado ao grampo que mantem juntas as tábuas dos cascos dos navios e significava também a própria união perfeita das tábuas. Na medicina era o nome dado a uma sutura que, certamente, também se desejava perfeita.

Uma relação precisa entre essas palavras se dá pela primeira vez quando os filósofos pitagóricos constroem a escala diatônica no século $5 \mathrm{aC}$ e definem matematicamente as relações entre os intervalos chamados consonantes, que são a oitava, a quarta e a quinta. Filolau de Crotona (séc. 5 aC)e Arquitas de Tarento (séc. $4 \mathrm{aC}$ ) são os primeiros seguidores de Pitágoras (séc. $6 \mathrm{aC}$ ) a deixarem escritos os ensinamentos do filósofo de Samos a quem é atribuída a construção da escala diatônica.

O propósito deste trabalho é apresentar uma versão ampla sobre a origem da escala diatônica. Que possa ser entendida não apenas com nossos atuais conhecimentos, principalmente aqueles referentes à matemática, mas também à luz do pensamento grego da época em que foi criada. Um pensamento que se pretende expor pelas relações da música com as crenças populares baseadas nos mitos e por sua utilização como forma de entendimento da ordem perfeita ("kosmos") do universo.

Além de mostrar o encontro primeiro da música com a harmonia, a pergunta que se procura responder é porque a escala musical pitagórica que contem intervalos perfeitos, mas também muitos intervalos imperfeitos do ponto de vista harmônico, resistiu por mais de 2 mil anos às inúmeras tentativas de alteração que procuravam torná-la mais própria à criação musical, mais agradável ao ouvido humano.

Vê-se, de início, que será necessário tratar dos conceitos de perfeição, de consonância e de harmonia quando aplicados à música e, certamente, aos intervalos que compõem as escalas. Estes conceitos serão expostos de acordo com o pensamento de Pitágoras e outros filósofos pré-socráticos.

São oferecidas também novas traduções para os fragmentos de Filolau de Crotona e Arquitas de Tarento que tratam das relações fundamentais da matemática com a música. Filolau e Arquitas são os primeiros filósofos, seguidores de Pitágoras, que escreveram sobre o pensamento do mestre e são, portanto, considerados fontes de grande autoridade.

Uma breve pesquisa etimológica relativa a palavras-chave sobre o assunto procura deixar mais claro o uso da palavra "harmonia" na sua passagem do concreto para o abstrato através da música e também sua futura importância para o desenvolvimento da filosofia.

Finalmente, é apresentado um exame do trecho do Timeu de Platão (c.428c. $348 \mathrm{aC}$ ) sobre a criação da alma do universo que, lido e comentado com base nas relações matemáticas criadas pelos pitagóricos, revela com maravilhosa precisão uma alegoria musical insuspeita. 


\section{A escala diatônica e o temperamento}

Nossa atual escala musical "temperada" 2 , resultante do temperamento da escala diatônica pitagórica, já sugere e aponta para alterações que foram introduzidas ao longo do tempo, entre o fim do século 16 e meados do século 19. A denominação "bem temperada" guarda uma relação íntima com o nome dado por J. S. Bach (1685-1750) a uma de suas mais conhecidas e famosas obras, "O cravo bem temperado" nome que reflete, na verdade, o reconhecimento da tentativa de obtenção do "temperamento igual", ou seja, o temperamento em que os intervalos entre os 12 semitons contíguos da escala mantém entre si uma relação numérica igual ${ }^{3}$. E admite-se também que na denominação "bem temperada" é clara a indicação de que se trata de algo nitidamente diferente do "temperamento mesotônico" (vide nota 8) em uso na época desde o Renascimento.

O novo temperamento que o grande mestre usou foi um dos vários temperamentos criados desde meados do século 17 à procura do temperamento igual. Andreas Werkmeister (1645-1706) é o nome mais conhecido na Alemanha e mesmo seu sistema mais evoluído, chamado Werkmeister III, era apenas próximo ao temperamento igual ${ }^{4}$. Daí se possa talvez inferir e, nesse caso, admirar, a precisão usada por Bach ao denominar de "bem temperada" a mais importante obra que abre para o homem a riqueza musical infindável que o temperamento proporciona.

Embora os conhecimentos científicos e principalmente os avanços da matemática do século 17 permitissem a formulação teórica do temperamento igual $^{5}$, a prática da afinação dos instrumentos não dispunha de meios para chegar nem mesmo à vizinhança do ideal, como hoje conseguimos, ou seja, chegar tão próximo à relação ${ }^{12} \sqrt{2}$ para o semitom a ponto do ouvido humano ser incapaz de discernir as diferenças e aceitar todos os intervalos como harmonicamente agradáveis ${ }^{6}$.

\footnotetext{
${ }^{2} \mathrm{Na}$ realidade a escala "temperada" que hoje usamos consegue chegar apenas muito próximo ao "temperamento igual", seu limite ideal. Vide nota (3).

${ }^{3}$ Esta relação é representada por ${ }^{12} \sqrt{ } 2=1,05987 \ldots$, um número irracional, incomensurável, o que torna teoricamente impossível, no limite, a realização da escala de temperamento igual.

${ }^{4}$ Werkmeister não era um teórico mas sim um prático. Seu sistema mais aperfeiçoado, o Werkmeister III, pode ter sido usado por Bach, embora haja quem defenda a tese de que Bach usou um sistema próprio.

${ }^{5}$ Entre os muitos teóricos que se destacam na procura do temperamento igual no século 17 figuram o Padre Marin Mersenne (1588-1648), autor da enciclopédica Harmonie Universelle e, descoberto recentemente pelo musicólogo Patrizio Barbieri, Juan Caramuel Lobkowitz (1696-1782), cujo tratado "Sobre os logaritmos musicais e o problema do temperamento musical" é o primeiro a indicar explicitamente a natureza logarítmica da escala musical. É interessante notar que o cálculo logarítmico foi introduzido na matemática pelo escocês John Napier em 1614 pela edição da "Descrição da maravilhosa regra dos logaritmos".

${ }^{6}$ Este ponto é cientificamente explicado por Hermann Helmholtz (1821-94) em sua grande obra On the sensation of tone, ao expor a teoria dos batimentos.
} 
As principais mudanças de entonação ${ }^{7}$ da escala diatônica pitagórica acontecem a partir do Renascimento e são conhecidas como o temperamento justo ${ }^{8}$ e o temperamento mesotônico ${ }^{9}$. Este último foi longamente utilizado a partir do fim do século 16. É curiosa a constatação de que toda a obra de Bach para o órgão tenha sido composta em tonalidades de poucas alterações na armadura de clave, no máximo três sustenidos ou três bemóis. A razão está no fato dos órgãos da época usarem o temperamento mesotônico, o que limitava bastante as possibilidades de modulação e obrigava o compositor a evitar tonalidades mais longínquas no desenvolvimento de suas obras ${ }^{10}$.

O rompimento da rígida estrutura da escala pitagórica, usada durante tantos séculos, tem início no século 15 com a introdução na Europa Continental do intervalo da terça natural, com relação 5/4, utilizada nos cantos populares da Inglaterra, que inspiravam compositores tais como John Dunstable

(1390-1453), capelão do exército do Duque de Bedford, que chefiou a invasão da Normandia no curso da Guerra dos Cem Anos (vide nota 8).

A partir da tièrce à l'anglaise como a chamavam os franceses, tem início uma verdadeira revolução na música da Europa Continental que envolve personagens famosos como Vincenzo Galilei

(1533-91), músico toscano pai de Galileo Galilei, e Gioseffo Zarlino (151790), poderoso mestre de capela da Catedral de São Marcos, em Veneza. Inúmeros outros músicos e teóricos aparecem à procura do temperamento.

Mas não é esta riquíssima fase da evolução da música ocidental o objeto principal deste trabalho. Ela é apenas fixada em breves linhas para estabelecer os limites no tempo do uso da escala diatônica pitagórica, e indica sumarissimamente as razões do seu desaparecimento com o advento do temperamento. Nosso propósito é aprofundar o conhecimento da origem daquela escala e procurar entender, como já foi dito, o caráter de imutabilidade a ela conferido durante tantos séculos.

\footnotetext{
${ }^{7}$ Neste trabalho entenderei por "entonação" a fixação dos intervalos da escala. Difere do termo afinação que representa a obtenção física da entonação desejada.

${ }^{8} \mathrm{O}$ temperamento justo (Just intonation, em língua inglesa) foi proposto primeiramente por Bartolomeo Ramos de Pareja em 1492 e, bem depois, por Gioseffo Zarlino (1517-90), mestre de capela da Catedral de São Marcos em Veneza. Zarlino, envolvido em ferrenha discussão com Vincenzo Galilei, (1533-91) pai de Galileo Galilei, tinha o objetivo de compatibilizar a escala pitagórica com a prática da terça natural (relação 5/4) que invadiu a Europa Continental, vinda da Inglaterra, depois da Guerra dos Cem Anos entre ingleses e franceses, assim chamada por seu grande número de batalhas entre 1337 e 1453

${ }^{9} \mathrm{O}$ temperamento mesotônico (mean intonation, em língua inglesa) procurava adotar uma terça natural, dividindo por 4 o coma pitagórico e distribuindo esta diferença entre os quatro intervalos de quinta que vão de dó a mi: do-sol, sol-ré, ré-lá, lá-mi. O cálculo do coma pitagórico é exposto no item 4 - O ciclo das quintas. A palavra "coma" é derivada do grego kómma que designava originariamente a estampa de uma moeda e, metaforicamente, um pequeno pedaço de alguma coisa, passando a designar também uma diferença e uma pequena parte de uma frase. Daí sua evolução para um sentido de vírgula tanto em latim como em inglês, onde mantém a grafia original, comma.

${ }^{10}$ Este ponto é observado e explicado por John Barnes em seu trabalho Bach's keyboard tempera-
} ment - internal evidence from the Well-tempered Clavier. 


\section{Música e harmonia: origens da escala diatônica}

\section{Origens}

O grupamento de sons que, de forma organizada, se apresenta como o mais antigo da música grega de que se tem notícia, reconhecida pelos musicólogos, é o tetracorde ${ }^{11}$, uma escala de quatro sons que, transformados na notação musical moderna corresponderiam, aproximadamente, às notas mi, fá, sol, lá $^{12}$. O intervalo entre a primeira nota (mi) e a última (lá) é um intervalo de quarta, "diatessaron"13, considerada a mais elementar consonância depois da oitava, "diapason"14. As relações matemáticas que presidem estes dois intervalos consonantes, assim como o também consonante intervalo de quinta, foram estabelecidas por Pitágoras, de acordo com seus discípulos e seguidores de seu pensamento filosófico ${ }^{15}$.

A descoberta teria ocorrido mediante experiências com cordas em vibração pelas quais se verifica que a oitava se dá na relação numérica $2: 1$, ou seja, quando o som mais grave provem de uma corda duas vezes maior do que a corda de onde provem o som mais agudo. $\mathrm{O}$ intervalo de quinta ocorre na relação 3:2, quando uma corda é 1,5 vezes maior que a outra. $O$ intervalo de quarta resulta como uma conseqüência das relações anteriores sendo sua relação igual a $4: 3^{16}$.

Assim, Pitágoras teria demonstrado não ser nenhum elemento físico, como a água, a terra, $\mathrm{o}$ ar ou o fogo $\mathrm{o}^{17}$, o ente primordial que rege a harmonia do universo. De acordo com seu pensamento este ente não era material nem transcendental, mas de uma categoria própria, algo despojado de um corpo, mas claramente definido. Através dele a recôndita ordem universal tornar-se-ia transparente. Este ente primordial era o número. Existem muitas referências sobre uma possível viagem de Pitágoras ao Egito onde teria absorvido as idéias referentes à importância fundamental dos números para o entendimento do universo.

\footnotetext{
${ }^{11}$ Sabe-se que a escala pentatônica, composta de cinco sons que correspondem, em termos modernos, às notas "pretas" do teclado, ou seja, aquelas que se intercalam à escala diatônica para formar a escala de 12 semitons, existiu em civilizações mais antigas, sem que, no entanto, tenha sido utilizada com alguma relevância na Grécia. Na realidade as escalas pentatônicas são varias, sendo a que nos referimos a mais comumente usada como exemplo.

${ }^{12}$ É aqui usada a palavra "aproximadamente", pois os sons que usamos hoje são de uma escala temperada, diferente pois da pitagórica. Este conceito é usado neste trabalho, sempre que não houver indicação diferente.

13 Palavra derivada de "dia", através, e "tessares", quatro.

14 Resultante de "dia", através, e "pason", de todas (as notas), que veio a denominar a oitava.

${ }^{15}$ Pitágoras nada deixou escrito. Os primeiros registros sobre estas relações matemáticas encontramse nos fragmentos de dois filósofos pré-socráticos, Filolau de Crotona e Arquitas de Tarento, ambas cidades da Magna Grécia no sul da Itália, onde Pitágoras, nascido na Ilha de Samos, na Jônia, viveu a maior parte de sua vida. Platão menciona os filósofos pitagóricos em várias partes de sua obra.

${ }^{16}$ A demonstração é simples: quando juntos, a quarta e a quinta formam a oitava. Assim $3 / 2$ x 4/3 = 2 .

${ }^{17}$ Como ensinaram outros filósofos pré-socráticos: Tales de Mileto, Anaximandro, Anaxímenes e Heráclito.
} 
Seja como for, com ou sem a influência egípcia, o pensamento pitagórico teve enorme influência no desenvolvimento da música, da matemática e da filosofia. Mesclado a esta inteligência, seu misticismo criador de uma peculiar seita religiosa levou Bertrand Russell a ele se referir como intellectually one of the most important men that ever lived, both when he was wise and when he was unwise. Mathematics, in the sense of demonstrative deductive argument, begins with him. ${ }^{18}$

Duas de suas grandes e famosas descobertas foram: a) na música, as relações numéricas das consonâncias entre dois sons; b) na matemática, o teorema que leva seu nome. Cabe destacar que ambas trazem contradições em si mesmas que, muito provavelmente, eram conhecidas pelo mestre de Samos e seus seguidores, mas permaneciam em segredo pelo código de comportamento imposto a todos os participantes de sua seita religiosa ${ }^{19}$.

Do teorema lembraremos aqui apenas que a equação dos triângulos retângulos $\left(\mathrm{a}^{2}+\mathrm{b}^{2}=\mathrm{c}^{2}\right)$, quando aplicada a um triângulo cujos lados que formam o ângulo reto são iguais e de valor igual a 1, torna o valor da hipotenusa igual a $\sqrt{ } 2$, um número irracional, incomensurável, cuja descoberta tem o condão de contradizer na base o próprio pensamento filosófico do mestre quando sustenta que a harmonia do universo tem por base os números pequenos e inteiros. Para Pitágoras, os números irracionais não podem existir, pois, neste caso, estaria admitida a existência do infinito. Para ele e seus seguidores o universo é uno e finito. Tal é a importância deste conceito que, como veremos adiante, seu ardoroso seguidor, o grande matemático Nicômaco de Gerasa (séc. $1 \mathrm{dC}$ ) em seu livro "O Manual dos Harmônicos", evita tocar em pontos que obrigatoriamente levariam à admissão dos números irracionais, embora certamente também tivesse conhecimento de sua existência.

Interessa-nos aqui, particularmente, a contradição que se encontra na incompatibilidade matemática do âmago da teoria pitagórica referente à música: a coexistência da lei das oitavas, governada pela relação 2:1 e a lei das quintas, governada pela relação 3:2, como mencionado anteriormente.

\section{O ciclo das quintas}

A forma mais usada hoje para demonstrar essa contradição se dá pelo uso de uma formulação conhecida como "o ciclo das quintas". Trata-se de um método muito simples para quem possui o moderno conhecimento de aritmética que,

${ }_{18}$ History of Western Philosophy, The Folio Society, London, 2004, p. 30.

${ }^{19}$ Alguns relatos narram o infortúnio de Hipasus, que teria sido condenado ao afogamento pelo crime de divulgação de segredos da seita. Um destes relatos é atribuído a Proclus, o ùltimo filósofo a presidir a Academia ateniense, no século $5 \mathrm{dC}$. 
no entanto, era um ramo da matemática pouco desenvolvido na Grécia Antiga $^{20}$. Ele pode ser encontrado em um sem número de autores, tão distintos como Sir James Dean em seu clássico Science and Music ${ }^{21}$ e Mario Henrique Simonsen em Ensaios Analíticos" ${ }^{22}$. Cada autor tem uma abordagem diferente e mais ou menos correta para a questão que pode ser exposta pela simples análise de uma escala diatônica de 7 oitavas, por exemplo, dó, dó ${ }_{1}$, dó ${ }_{2}, \ldots$, dó ${ }_{7}$.

Partindo-se de dó em intervalos de quintas chegaremos após 12 quintas à nota dó ${ }_{7}$, que é a mesma obtida com intervalos de oitavas repetidos 7 vezes. No entanto $2^{7}=128$, enquanto $1,5^{12}=129,74 \ldots$. Esta diferença $129,74 \ldots: 128$ é conhecida como o "coma de Pitágoras" e nela está a origem das dissonâncias da escala pitagórica, que inexistem apenas nos intervalos de quarta, quinta e oitava. Não é por outra razão que estes intervalos chegam até nossos dias com a denominação de "justos" em teoria musical ${ }^{23}$. Os demais, a segunda, a terça, a sexta e a sétima são maiores ou menores, nunca são ditas justas ${ }^{24}$.

Como dissemos, a demonstração pelo ciclo das quintas é uma forma moderna de explicar a existência de uma incompatibilidade nas descobertas de Pitágoras, que foi percebida na época sem a necessidade de uma extensão de sete oitavas na escala. A maior escala admitida no período clássico grego, o chamado Grande Sistema Perfeito, abarcava apenas duas oitavas e a extensão das melodias da época não costumava superar nem mesmo uma oitava. Apenas Platão, como mostraremos no item 10, fez o recôndito uso de uma escala de quatro oitavas e uma sexta em seu famoso diálogo, o Timeu, em que este filósofo pitagórico relata a Sócrates, Crítias e Hermócrito a criação da alma do universo.

\section{A oposição entre Pitágoras, Aristoxeno e Didmo}

Uma grande oposição ao sistema pitagórico existiu no início do século 4 aC, liderada por Aristoxeno de Tarento, contemporâneo de Aristóteles (384$322 \mathrm{aC}$ ), considerado um grande conhecedor da teoria musical de seu tempo. Aristoxeno tem a seu favor o fato de ter deixado por escrito seu pensamento sobre a teoria e a prática da música.

\footnotetext{
${ }^{20}$ Os gregos foram grandes geômetras, estando a prova cabal nos "Elementos" de Euclides. A aritmética, no entanto, não era tão desenvolvida quanto a geometria.

${ }^{21}$ Science and Music, Sir James Dean, New York: Dover Publications Inc., p. 166.

${ }^{22}$ Ensaios analíticos, Mario Henrique Simonsen, Fundação Getulio Vargas Editora, $3^{\text {a }}$ edição, p. 91.

${ }^{23}$ Podem ser aumentados ou diminuídos, nunca maiores ou menores.

${ }^{24}$ Passam-se séculos de "ajustamentos" até os 7 modos gregos originais reduzirem-se a dois, que dão origem aos nossos atuais modos "maior" e "menor".
} 


\section{HUMANAS}

Em seu livro "Elementos de Harmonia" em três volumes ${ }^{25}$, que é o mais completo e detalhado tratado musical da Grécia Antiga que nos chega aos dias de hoje, ele discorda frontalmente dos pitagóricos no tratamento matemático usado para a definição dos intervalos musicais e, portanto, das escalas, aceitando apenas a consideração da existência das concordâncias naturais referentes à oitava, à quarta e à quinta.

Aristoxeno era sobretudo um músico. Para ele, qualquer intervalo menor do que uma quarta na escala pitagórica é necessariamente dissonante ${ }^{26}$ (Elementos de Harmonia, Volume 1, p. 6-10), argumento que lhe permitiu afirmar que a arte musical não pode se submeter a relações puramente matemáticas. Lutou por uma escala mais livre e agradável ao ouvido humano, e, por conseguinte à alma, condenando sobretudo o intervalo de terça da escala pitagórica, que considerava insuportável.

Suas teses não prosperaram. Em alguma medida devido a seu próprio caráter e comportamento. Os relatos históricos dão conta de sua extrema vaidade e prolixidade, esta contida em grande número de obras literárias e filosóficas de valor duvidoso, hoje perdidas e raramente citadas, e aquela refletida em sua pretensão frustrada de suceder Aristóteles no Liceu. Segundo Henry S. Macram, Aristoxeno não respeitou a morte de seu mestre Aristóteles. Lê-se às páginas 86 e 87: "[...] sua posição no Liceu deve ter sido importante, pois ele alimentava a esperança de suceder seu mestre, e seu desapontamento e desgosto com a indicação de Teofrasto transpareceu na linguagem desrespeitosa com que tratou o poderoso falecido. Na verdade, se os relatos são verdadeiros, o desejo de ser reverenciado foi um pecado obsessivo: ele teria desvalorizado Platão e, maliciosamente, propagado histórias escandalosas, ouvidas de seu pai, sobre a vida doméstica de Sócrates."

Mas não me parece justo atribuir apenas ao caráter de Aristóxeno e à sua irrelevante (embora volumosa) obra filosófica a não aceitação de suas proposições estéticas na música. É mas provável que suas atitudes tenham, na realidade, apenas contribuído para seu esquecimento como filósofo e, também, em menor proporção, como teórico musical. Quanto à prolixidade, no entanto, não é necessário confiar em relatos de terceiros. A simples leitura de seu livro é suficiente para comprová-la.

Outra famosa discordância em relação aos pitagóricos acontece pela tentativa de ajuste da escala que se deve a Didmo, um músico e matemático do séc. $1 \mathrm{dC}$. Para ele não foi preciso estender a escala por 7 oitavas para perceber as dissonâncias, principalmente aquela do intervalo de terça. A música da época usava uma extensão pequena que mal ultrapassava uma oitava, como já foi dito.

${ }_{25}$ Aristoxenou Armoniká Stoicheia. Traduzido e comentado por Henry S. Macran (The Harmonics of Aristoxenus, Oxford at The Clarendon Press, 1902).

${ }^{26}$ Antecipando-se assim em cerca de 400 anos à posição de Didmo, comentada na nota 26 e também, em cerca de 2.200 anos à teoria dos batimentos formulada por Helmholz no século 19 . 
Sendo basicamente homofônica, suas melodias não exigiam a entonação e os acordes demandados pela polifonia. O ajuste proposto por Didmo incluía as seis primeiras notas da escala, por exemplo, de dó a lá. Usando a lei das quintas (relação 3/2) pode-se verificar com poucos e simples cálculos que a entonação da terça se dá na relação $81 / 64^{27}$. Como já era sabido na época, a terça pitagórica na relação 81/64 está aumentada em 1/64 em a relação à terça natural ou pura, cuja relação é $5 / 4$, pois $5 / 4=80 / 64$. Didmo propôs então distribuir esta diferença pelas 4 quintas usadas para se chegar de dó (C) a mi (E), o que permitiria obter uma terça pura pelo preço de alterar as quintas no valor de 1 / 256, ou seja, a quarta parte da coma pitagórica. Esta diferença passou a ser chamada de coma de Didmo.

Não há notícias de que este sistema tenha sido praticado na Antiguidade, até onde minha pesquisa se estendeu. Mas ele virá a ser a base do temperamento mesotônico que veio a ser usado cerca de 15 séculos depois, como dito anteriormente.

\section{Sobre a construção da escala de oito sons}

É de Nicômaco de Gerasa, matemático e músico do século $1 \mathrm{dC}$, que nos chega a mais remota e completa narrativa que atribui a construção da escala diatônica à genialidade do filósofo de Samos. Seu livro The manual of Harmonics ${ }^{28}$, como o próprio autor declara no Capítulo 1 , atende ao pedido de uma "nobre Majestade", possivelmente uma princesa egípcia, "que deseja ser iniciada no estudo dos intervalos musicais e suas relações harmônicas". Desculpa-se também logo de início declarando se tratar de uma tentativa de explicar um assunto complexo e difícil em um simples comentário (seu livro!) prometendo enviar um tratado bem mais articulado e compreendendo vários volumes ${ }^{29}$ assim que tivesse mais tempo livre e descansado da viagem ${ }^{30}$.

Depois de tratar nos primeiros capítulos das espécies dos sons vocais (canto e discurso), da música dos planetas e de como foram descobertas as relações matemáticas que regem os intervalos musicais, ele registra, pela primeira vez, a famosa lenda dos ferreiros com seus sons consonantes e dissonantes, resultantes das batidas dos martelos nas bigornas.

\footnotetext{
${ }^{27} \mathrm{O}$ cálculo é simples: por exemplo, partindo-se da nota dó (C) e aplicando-se a lei das quintas duas vezes chega-se primeiro, de dó (C) a sol (G), a 3/2 e em seguida, de sol (G) a ré (D1), a 9/4. Para voltar a ré (D) divide-se $D_{1}$ por 2 chegando-se a 9/8. Repetindo-se a operação com a aplicação de dois intervalos de quinta a partir de ré (D) em 9/8 chega-se a mi (E) em 81/64.

${ }_{28}$ Traduzido do grego, Encheirídion Harmonikês, por Flora R. Levin, Phone Press, Grand Rapids MI, USA, 1994.

${ }^{29}$ Obra hoje perdida, que provavelmente foi usada por Boécio em seu De institutione musica.

${ }^{30}$ Tudo indica que Nicômaco ditou este manual a um escriba "ex tempore", ao modo dos antigos, e estivesse em viagem de navio. 
Esta lenda será repetida ao longo da Idade Média por autores como Iamblico (c.245-325 dC) e Boécio (c.480-525 dC). Ela alega terem sido os sons produzidos por aqueles ferreiros que inspiraram Pitágoras na descoberta das relações das mais puras consonâncias, por obra da divindade.

É clara a intenção de Nicômaco em sublinhar o caráter de semideus que Pitágoras havia adquirido entre seus seguidores da Magna Grécia. Mas a inverossimilhança daquele relato o fez ser sempre tratado como lenda. Em seguida Nicômaco retoma o tom da objetividade e descreve as reais experiências que conduziram àquelas relações matemáticas através de um instrumento denominado monocórdio, pelo qual são feitas medidas sobre uma única corda, variando-se o ponto de apoio pelo uso de um cavalete móvel.

Chega-se então ao ponto central da exposição, que trata especificamente da "divisão da oitava no gênero diatônico" (to diatonon genos). O texto, embora breve, relata com detalhes a obtenção da escala de oito sons pelo uso de dois tetracordes, separados pelo intervalo de um tom inteiro, formando assim uma oitava:

mi, fá, sol, la, si, dó, ré, mi

$\mathrm{E}, \mathrm{F}, \mathrm{G}, \mathrm{A}, \mathrm{B}, \mathrm{C}, \mathrm{D}, \mathrm{E}_{1}$

Onde E, F, G, Aé o primeiro tetracorde, A, B é o intervalo de um tom inteiro e B, C, D, E é o segundo tetracorde. É constituída assim a escala de oito sons que tantos tentaram realizar, mas que só a Pitágoras teria sido permitido.

É importante frisar o enorme alcance deste passo na história da música, independentemente do quanto de verdade histórica possa ser atribuída exclusivamente a Pitágoras.

\section{Antecedentes históricos e mitológicos}

É opinião generalizada entre os estudiosos que o início da música como manifestação artística na Grécia Antiga compreende um período em que os registros históricos estão misturados com a tradição oral, os costumes e as crenças religiosas do povo. Dentro destes componentes é importante extrair a informação de que aquelas mais remotas manifestações musicais eram baseadas no tetracorde $^{31}$. Eram cantorias que acompanhavam procissões chamadas falofórias, ou Dionísias rurais, em que se clamava ao deus Dioniso pela fertilidade nos campos e nos lares. Em seguida apareceram as Dionísias da cidade onde uma peça coral,

${ }^{31}$ Hermann Helmholtz (On the sensations of tone; p. 255). 
denominada ditirambo, em forma de poesia lírica, era entoada por um cantor principal, o corifeu, e a parte do coro era cantada por personagens considerados amigos(as) de Dioniso ${ }^{32}$.

Assim, o caráter religioso destas festividades reforça o componente mitológico da escala de quatro sons e atribui uma dimensão sagrada ao tetracorde. Em seus primórdios, então, a música na Grécia guarda uma característica de imutabilidade que se prolonga por muito tempo. Interessam-nos aqui particularmente os textos de variados autores que, nas referências musicais, incluem importantíssimos relatos sobre a invenção da lira, que a atribuem tanto a Hermes (Mercúrio na civilização latina) como a Apolo (o deus das artes e da claridade). Aparecem nestes relatos personagens importantes como Orfeu, Lino (filho de Apolo) e Anfião, o construtor das sete portas de Tebas, que usou os sons da lira para movimentar as pedras que ninguém conseguia mover.

O principal poeta que atribui a invenção da lira ao deus Hermes é o autor do chamado Hino Homérico a Hermes. Neste relato lê-se a famosa história daquele deus gerado por Maia em uma caverna ${ }^{33}$. Ainda recém-nascido ele inventa a lira de 7 cordas usando o casco de uma tartaruga e, como $\operatorname{cordas}^{34}$, as tripas de bovinos furtados do rebanho de seu irmão Apolo. Inicialmente furioso, mas aos poucos encantado com os sons que o menino produzia com aquele instrumento, o deus da claridade teria concordado em recebê-lo em troca do perdão ao furto cometido. Hermes começava assim sua carreira de astuto comerciante ${ }^{35}$.

Como já dissemos no início deste trabalho, a palavra mousike significava, na realidade, todas as artes patrocinadas pelas musas e muitas vezes, mais especificamente, apenas o conjunto música e poesia. E a lira, o mais venerado instrumento musical por sua excelência no acompanhamento do canto, está sempre associada a Apolo, o deus da ordem e da claridade. No Hino Homérico a Apolo ela é mencionada inúmeras vezes, sempre com destaque. Já no início do poema, nos versos 130 e 131 que narram o nascimento do deus, aparecem juntos o arco e a lira ${ }^{36}$.

Ao se acompanhar com a lira, o cantor permite aos seus ouvintes o entendimento da poesia que suscita o enriquecimento da alma. Assim, Apolo tem a lira como inseparável companheira em sua condição de deus da ordem e da claridade.

\footnotetext{
${ }^{32}$ No dicionário grego-inglês de Liddell e Scott é apontada a palavra Baco (Bakchos) como forma tardia do nome Dioniso.

${ }^{33}$ A deusa Maia é levada por Zeus a uma caverna, sob sigilo total, para a proteção do futuro deus.

${ }^{34}$ De fato a palavra "chordé" em grego significa uma corda feita de tripas.

${ }^{35}$ Carreira que teria imediato seguimento com a invenção da "syrinx", ou flauta de Pã, que também negocia com Apolo, recebendo como pagamento o caduceu.

${ }^{36}$ Estes versos, com tradução do autor, encontram-se no Anexo II.
} 
É a importância deste tema, tendo a lira como elemento central, que levou Flora R. Levin em seu comentário ao capítulo 5 do The Manual of Harmonics (p. 211), a afirmar que "[...] certamente a lira não teve sempre 7 cordas; existe um estágio muito anterior da lira, associado a Lino, um filho de Apolo". De acordo com esta lenda, Lino havia sido ensinado por seu pai na arte de tricórdio, a lira de três cordas. A esta ele adicionou uma quarta corda - a "lichanos" ou corda do dedo indicador - e assim inventou a lira de quatro cordas, no mais antigo tetracorde. Foi a partir dos limites entre o som mais grave e o som mais agudo, o intervalo de quarta que cria a mais elementar consonância como Nicômaco a chama no capítulo 12 de seu Manual of the Harmonics, "que todas as escalas musicais da Grécia Antiga vieram a ser desenvolvidas".

A importância do tetracorde que aqui se procurou demonstrar é reconhecida tanto na sua sacralidade pelas referências míticas, como na formação das escalas musicais ${ }^{37}$ pelos relatos históricos que passam, por exemplo, por Aristoxeno, Platão, Nicômaco, Didmo, Iamblico, e tantos outros.

\section{A construção da escala com base em textos e fragmentos de seguido- res de Pitágoras}

Vamos caminhar agora na direção do ponto mais importante da construção da escala de oito sons cujo alcance é a oitava, ou seja, a escala de sete notas à qual mais uma nota foi adicionada, permitindo o aparecimento dos instrumentos tão reclamados pelos músicos. No caso dos instrumentos de corda, a lira de oito cordas.

Esta criação, de acordo com Nicômaco, somente foi permitida a Pitágoras que, como já dissemos, em certas ocasiões teria sido considerado um semideus, especialmente em cidades da Magna Grécia como Crotona e Tarento, onde eram particularmente importantes e numerosas as seitas de seus seguidores. Vários outros músicos tentaram a formação da escala com o alcance de uma oitava, mas fracassaram e muitos foram duramente castigados. A sacralidade da escala de sete sons, composta por apenas dois tetracordes em conjunção não permitia qualquer tipo de alteração. Nem mesmo uma tentativa de Terpandro (séc. $7 \mathrm{aC}$ ) foi aceita ${ }^{38}$. O que é atribuído a Pitágoras foi a sábia manutenção dos dois tetracordes, mas agora não mais em conjunção porém em disjunção, separados pelo intervalo de um tom inteiro, como já foi dito anteriormente.

\footnotetext{
${ }^{37}$ Embora aqui estejamos tratando da escala diatônica, o intervalo de quarta tem a mesma importância tanto na formação da escala cromática como na da escala enarmônica, cujo desenvolvimento está certamente fora do escopo do presente trabalho.

${ }^{38}$ Flora R. Levin, The manual of Harmonics, Phane Press, 1994, p. 75.
} 
Quando os dois tetracordes em conjunção formavam o heptacorde, tínhamos:

$1^{\circ}$ tetracorde

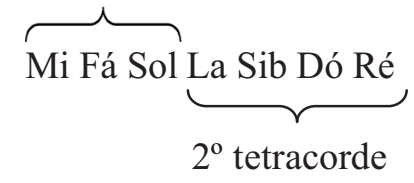

O primeiro era denominado "meson" ou o tetracorde das notas médias. O segundo tinha o nome de "synemmenon" ${ }^{39}$, ou seja, das notas conjuntas. É importante notar a formação idêntica dos dois tetracordes, com intervalos de meio tom, um tom, e um tom de mi a lá e também de lá a ré. Ao separá-los manteve-se certamente a escala com dois tetracordes, porém agora em disjunção, mediante a alteração de Sib para Si e o acréscimo da oitava nota, Mi.

$1^{\circ}$ tetracorde

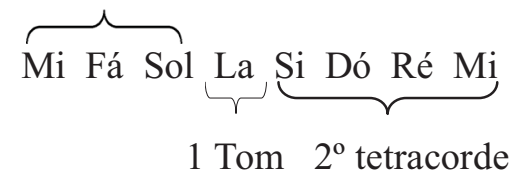

O primeiro tetracorde manteve o nome "meson" e o segundo passou a ser chamado "diezeugmenon"

A nota Lá do primeiro tetracorde, chamada "mese", que se pode traduzir como "média", continua mantendo a importância que tinha ao ser a nota comum dos tetracordes em conjunção e passa a ser agora a nota comum dos intervalos que, juntos, formam o octacorde: o tetracorde (diatessaron) e o pentacorde (diapente).

\section{Mi Fá Sol Lá Si Dó Ré Mi \\ Tetracorde Pentacorde}

Através dela é realizada a perfeição da oitava, pois nela se dá o encontro do intervalo de quarta com o intervalo de quinta ${ }^{41}$. Neste encontro está uma das chaves do encantamento que Platão percebeu no pensamento pitagórico.

\footnotetext{
39 Palavra derivada do verbo "syníemi", que significa juntar.

${ }^{40}$ Palavra derivada do verbo "diazeugnymai" que significa separar, desunir.

${ }^{41}$ Os intervalos de quarta e quinta são simétricos e complementares em relação à oitava. Na escala ascendente de dó $(\mathrm{C})$ a quarta é alcançada na nota fá $(\mathrm{F})$ e a quinta na nota sol $(\mathrm{G})$ enquanto na escala descendente a quarta é alcançada na nota sol $(\mathrm{G})$ e a quinta na nota fá $(\mathrm{F})$. 
Duas notas, ou médias matemáticas como veremos adiante, em posições absolutamente simétricas em relação à oitava, iguais ou diferentes ao mesmo tempo, como se explica na nota 40. A extraordinária simetria assim obtida é um dos mais belos mistérios que a escala diatônica nos apresenta. A escala mostrada, começando e terminando em Mi refere-se ao modo dórico, de onde surgem os demais modos da música grega antiga.

E, se Pitágoras usou uma lógica puramente sensorial neste desenvolvimento, o raciocínio estritamente matemático em que se baseia sua teoria da harmonia universal fundada nos números pequenos e inteiros outra coisa não faz senão confirmar aquilo que os sentidos mostraram em relação à perfeição, pois a junção da quarta (relação 4/3) com a quinta (relação 3/2) conduz à oitava (relação 2/1) também chamada de "harmonia" pelos gregos. De fato, $4 / 3 \times 3 / 2=12 / 6=2$. Nasce neste momento, no dizer de Platão, a teoria dos harmônicos ${ }^{42}$.

Como relacionar esta palavra chave - harmonia - às descobertas matemáticas do filósofo de Samos e seus seguidores? Em que sentido a palavra harmonia passa a ter tanta importância na música, na matemática e, posteriormente, em tantos outros campos do conhecimento, em particular na filosofia?

\section{Harmonia - do concreto ao abstrato}

É Arquitas de Tarento, astrônomo, matemático e filósofo, seguidor de Pitágoras e considerado um dos importantes filósofos pré-Socráticos, embora tenha sido contemporâneo de Platão, quem nos deixa registrada a mais clara relação da matemática com a música, em seu fragmento $\mathrm{n}^{\mathrm{o}} 2^{43}$ cujas principais partes traduzimos a seguir. Diz ele:

Existem três médias na música, uma a aritmética, a segunda geométrica, a terceira "hypenantia", conhecida como média harmônica. Amédia aritmética existe quando os três termos se apresentam na seguinte proporção: o segundo supera o primeiro tanto quanto o terceiro supera o segundo. A geométrica, quando o primeiro termo está para o segundo assim como o segundo está para o terceiro. A "hypenantia”, que chamamos de média harmônica, existe quando da mesma forma que o primeiro termo excede o segundo por uma sua própria parte, o termo médio (o segundo) excede o terceiro por essa parte do terceiro.

\footnotetext{
${ }^{42}$ Platão desprezará as verdades obtidas através dos sentidos e dará valor apenas àquelas resultantes do pensamento puro, da lógica que conduz à dialética e finalmente à filosofia.

${ }^{43}$ Fragmento $^{\circ}{ }^{\circ}$, conforme registrado em Diels/Kranz - Die Fragmente der Vorsokratiker I, Weidmann, 2004, pp. 435-36. Anterior a este fragmento de Arquitas é o importante fragmento $\mathrm{n}^{\mathrm{o}} 6$ de Filolau de Crotona, parcialmente apresentado no Anexo I. 
Trata-se de uma apresentação aritmética totalmente baseada em proporções, forma clássica da época que soa estranha e de difícil compreensão hoje em dia, acostumados que estamos com o pensamento algébrico que os gregos não possuíam. Ernest McClain em seu livro Pythagorean Plato considera, no entanto, que nossas atuais formas algébricas de apresentação da média aritmética $\mathrm{A}+\mathrm{B} / 2$ e da média harmônica $2 \mathrm{AB} / \mathrm{A}+\mathrm{B}$ são singularmente mascarantes.

A palavra "hypenantia" foi deixada no texto acima em grego, propositalmente, pois é dela que cuidaremos em seguida, procurando mostrar que é a partir no entendimento do seu significado que se encontrará a relação explicita entre música e harmonia. Hypenantia foi muitas vezes traduzida ${ }^{44}$ por expressões tais como "contrária", "contraposta", "sub-contrária" ou outras equivalentes. Todas elas refletem um pensamento filosófico, o que é natural para tradutores afeitos e ligados à filosofia ${ }^{45}$ mas não necessariamente à música. Mas estas expressões não facilitam a compreensão desta parte crucial do texto de Arquitas e, mais importante, não permitem o entendimento da ligação que é feita, musicalmente, à expressão "harmônica". E é nesta época que o conceito de perfeição da palavra harmonia é estendido à música. É pois necessário que a tradução permita considerar os conceitos matemáticos e musicais envolvidos, aqueles que dão sentido às descobertas de Pitágoras. Faremos isso logo mais adiante, após examinar primeiramente o significado musical das médias aritmética e geométrica.

A primeira, aritmética, é facilmente associada ao intervalo de quinta. Isto porque tomando-se, por exemplo, um intervalo definido pelos números 6 e 12 , referindo-se o número 6 à nota mais grave e 12 à nota mais aguda, uma oitava acima, ( usando-se o conceito de freqüências) a média aritmética 9 refere-se a uma nota exatamente uma quinta acima da nota mais grave, pois 6 × $3 / 2=9$. Se a nota mais grave for um dó, a que está representada pelo número 9 será um sol. A segunda, geométrica, está associada ao intervalo de oitava, pois as oitavas são expressas geometricamente pelo fator 2 . Se uma nota musical está associada ao valor $\mathrm{x}$, suas oitavas terão $\mathrm{o}$ valor $2 \mathrm{x}, 4 \mathrm{x}, 8 \mathrm{x}, \ldots .2^{\mathrm{n}} \mathrm{x}$.

Retomemos agora a definição sobre a "hypenantia", conhecida como média harmônica. Diz o texto que a média harmônica entre dois termos acontece quando o primeiro supera o segundo por uma parte do seu valor,

\footnotetext{
44 Diels a traduz por entgegengezetste que significa "oposta". Gerd Bornheim usa o termo "contraposta" e Kathleen Freeman emprega a palavra subcontrary o que remete a uma acepção filosófica apoiada na matemática como pode ser observado pelas notas de Ivor Thomas ao traduzir textos de Nicômaco de Gerasa no volume I de Greek Mathematics, onde é clara a oposição dos termos, ora no numerador, ora no denominador, nas expressões que usam a palavra hypenantia em médias conhecidas na matemática grega.

${ }^{45}$ Heráclito é um dos primeiros filósofos, senão o primeiro, a usar o conceito de harmonia, deixandoo registrado em vários fragmentos como os de número $8,48,51$ e 54 (vide tradução do $\mathrm{n}^{\circ} 51$ no Anexo II). No fragmento 54 diz que "A harmonia invisível é mais forte que a visível" dualidade que nos remete ao Timeu de Platão onde este mesmo conceito heraclitiano é usado no trecho em que é descrita a criação da alma do universo.
} 
da mesma forma que o segundo supera o terceiro por esta mesma parte do valor do terceiro termo. Como a média harmônica é, ainda hoje, muito pouco usada, sua definição parece mais complicada do que de fato é. Um exemplo numérico a tornará evidente.

Retomemos os números 6 e 12, que determinam uma oitava, e procuremos determinar a média harmônica. As expressões que satisfazem a definição de Arquitas são: $12-4=8$, da mesma forma que $8-2=6$. Ou seja, retira-se $1 / 3$ de 12 para se chegar de 12 a 8 assim como, de 8 , é retirado $1 / 3$ de 6 para se chegar a 6 . Neste exemplo a média harmônica tem o valor 8 . E nela se encontram a quarta e a quinta formando a oitava, pois partindo da nota dó com valor 6 chega-se a fá com valor 8 , pois $6 \times 4 / 3=8$, o que levou o filósofo de Tarento a deixar registrados os valores das médias que existem na musica : "[...] a terceira, "hypenantia", que chamamos de média harmônica[...]". Note-se que está nela, na média harmônica, o encontro entre a quarta e a quinta para a formação da oitava. Registre-se também que os números 6,8,9,12 formam o que os pitagóricos consideravam o "tetraktis musical" , cuja explicação está fora do escopo deste trabalho.

A acepção puramente filosófica também está contida no texto quando este se mostra em sua clareza musical. Vimos que desde sua mais longínqua origem a palavra harmonia está ligada à junção de partes desiguais para formar algo perfeito. Harmonia não existe quando as partes são iguais, pois neste caso existe apenas identidade. Entre os pré-socráticos é Heráclito um dos filósofos que mais tratou desta questão. Em seu fragmento $n^{\circ} 51$, por exemplo, diz ele que a harmonia é causada por tensões contrárias exatamente como a do arco e a da lira, imagem que reflete sua teoria da fusão dos opostos. No Anexo II são apresentadas, com comentários, traduções do fragmento 51 e das linhas 130 e 131 do Hino Homérico a Apolo que também tratam do arco e da lira.

$\mathrm{Na}$ figura que se segue são indicados os intervalos de quarta, quinta e oitava, com seus respectivos valores numéricos, assim como foram calculados pelos pitagóricos no século 5 a $\mathrm{C}$.

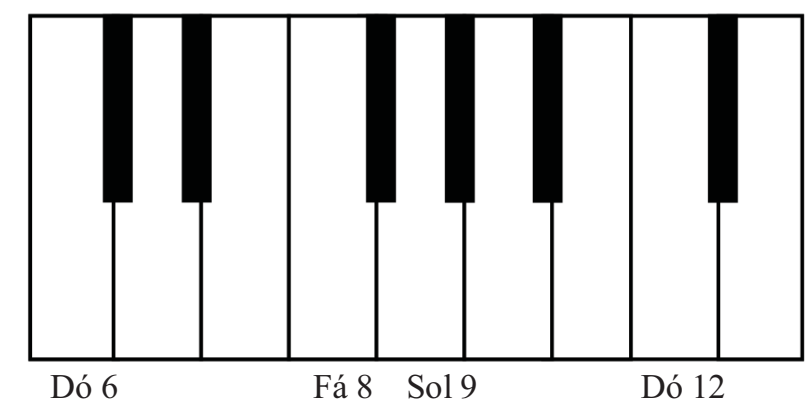


É necessário agora aprofundar a tradução do texto de Arquitas para entender o uso da palavra "hypenantia" que foi historicamente traduzida por "contrária" ou "contraposta". O primeiro significado que os dicionários apresentam é "o que se opõe contrariamente". E ao esquadrinhar o verbete, aparece explicitamente esta acepção em filosofia, como, por exemplo, usada em Heráclito. A segunda possibilidade de tradução abonada pelos dicionários é diferente: hypenantía significa também "o encontro". Assim, com este significado, a tradução e o quadro etimológico musical mostram-se claros, pois o intervalo de quarta e o intervalo de quinta ao formar a oitava encontram-se exatamente no valor 8 , passando a média assim obtida a ser chamada de média harmônica.

Estes são alguns dos mistérios dos números pequenos e inteiros $(1,2,3) \mathrm{e}$ das correspondentes consonâncias musicais percebidas pelos humanos, que os seguidores de Pitágoras acreditavam terem sido revelados ao mestre de Samos pela divindade. Nos números estariam contidos os segredos do "Kosmos" que caberia ao homem desvendar.

Resta-nos agora examinar o sentido original da palavra "harmonia". Como já foi dito na Introdução, em seu significado mais remoto harmonia era o grampo que mantem unidas as tábuas dos cascos dos navios. Significava também a própria união das tábuas, de importância extrema para a segurança da vida no mar. Tinha, portanto, o sentido de uma união perfeita. Na medicina, harmonia significava uma sutura. Na música, a perfeição da oitava foi consagrada com denominação de "harmonia". Uma das formas de expansão deste sentido de perfeição, do concreto para o abstrato, se dá, portanto, através da música, na passagem do século 6 para o Século 5 a.C. Suas extensões estão registradas não apenas nos fragmentos de Arquitas de Tarento e Filolau de Crotona, mas também de outros pré-socráticos como, por exemplo, Heráclito de Éfeso, em contexto filosófico citado anteriormente.

A percepção, ou idealização, de uma interferência divina nesta mensagem de revelação do "kosmos", aos humanos, a ordem perfeita do universo, que se encontra nos ensinamentos de Pitágoras, tem uma enorme força no pensamento grego. Ela chega a seu apogeu na obra de Platão, especialmente no trecho do Timeu em que é exposta a forma pela qual o Demiurgo criou a alma do universo, comentada brevemente a seguir.

\section{Platão e Timeu - a criação da alma do Universo}

Neste diálogo, muito conhecido e estudado na Idade Média, encontrase a descrição da criação do universo que teve enorme influência tanto na filosofia quanto na teologia desde sua aparição. Em sua parte central, Timeu, 


\section{UMANAS}

um filósofo, matemático, músico e astrônomo da cidade de Locri, situada na Magna Grécia ${ }^{46}$, descreve a formação da alma do universo em extenso e belíssimo discurso. O relato é prenhe em linguagem matemática. Sua análise detalhada permite também admiti-lo como uma alegoria musical em função dos conceitos pitagóricos sobre os intervalos das escalas musicais e sua relação com os números. A dificuldade de leitura e compreensão desta parte do texto, tão propalada por muitos de seus comentadores, reside exatamente no fato de Platão usar a teoria dos harmônicos para relacionar categorias filosóficas, como "o ser" ${ }^{\prime \prime 7}$ e o "vir a ser", assim como o "divisível" em relação ao "único e indivisível". E na forma como é descrita a criação da alma do universo essas relações aparecem em sua plenitude, sugerindo, se me permitem, que o Demiurgo era antes de tudo um filósofo músico-matemático, ou o inverso.

Diz Timeu que o Demiurgo usou nessa construção o que era "idêntico" e o que era "diferente", ou se quiserem, o "mesmo' e o "outro". Para mesclá-los, tarefa naturalmente muito difícil, ele usou o "ser" (ousia). E quando, com a intervenção do "ser", ele conseguiu mesclá-los e deles fez, de três, um, pôs-se em seguida a distribuir o todo dessa mescla em tantas partes quantas eram necessárias. E cada parte era uma mistura do "idêntico", do "diferente" e do "ser". E ele começou a realizar a divisão da seguinte forma : primeiramente ele tomou uma parte do todo; em seguida tomou outras seis partes iguais ao dobro, triplo, quádruplo, oito, nove e vinte sete vezes o valor da parte inicial.

É dessa parte da descrição que os comentadores desse diálogo dispõem o universo assim descrito na forma de um lambda:

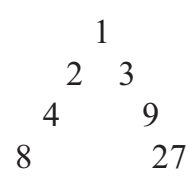

O texto prossegue explicando também literal e detalhadamente como os intervalos assim criados foram preenchidos com outras partes retirados do todo, usando formas de expressão idênticas às de Arquitas em seu fragmento $\mathrm{n}^{\circ} 2 \mathrm{e}$ indicando que cada intervalo é preenchido com duas partes, cujos valores são, se calculados rigorosamente como o texto indica, iguais à média harmônica e a média aritmética. Tomando-se como exemplo o primeiro intervalo $1-2$, teremos:

\footnotetext{
${ }_{46}$ Ao contrário dos demais diálogos, Timeu é considerado um personagem fíctício. Platão não poderia colocar este discurso na boca de Sócrates que não possuía as qualificações de matemático e astrônomo. É possível que ele tenha se inspirado em Arquitas, também seu contemporâneo, amigo e possuidor daquelas qualificações, mas não desejasse uma referência tão explícita na parte essencial de sua cosmogonia.

${ }^{47}$ A palavra usada é "ousía", derivada do verbo ser (eimí) é também traduzida como "o que é" ou "essência".
} 
Diz então Timeu que todos os intervalos estabelecidos na relação 4/3 são preenchidos com duas outras partes retiradas do todo, aplicadas em valor 9/8. Assim, no intervalo 1 - 4/3, (o primeiro tetracorde), aparecerão os valores 9/8 e $81 / 64$ :

$$
\begin{array}{llll}
9 / 8 & 81 / 64 & 4 / 3 & \text { (pois } 9 / 8 \times 9 / 8=81 / 64 \text { ) }
\end{array}
$$

No intervalo $3 / 2-2$, (o segundo tetracorde, também estabelecido na relação 4/3), surgirão os valores 27/16 e 243/128:

$\begin{array}{llll}3 / 2 & 27 / 16 & 243 / 128 & 2\end{array}$ (pois $3 / 2 \times 9 / 8=27 / 16$ e $27 / 16 \times 9 / 8=243 / 128$ )

Estes valores representam precisamente a escala diatônica pitagórica:

$$
\begin{array}{cccccccc}
1 & 9 / 8 & 81 / 64 & 4 / 3 & 3 / 2 & 27 / 16 & 243 / 128 & 2 \\
\text { Dó Ré } & \mathrm{Mi} & \mathrm{Fa} & \mathrm{Sol} & \mathrm{La} & \mathrm{Si} & \text { Dó }
\end{array}
$$

Esta é a escala apresentada nas páginas 6 e 8, quando se toma seu início pela nota Dó, em vez de Mi. Todos os demais intervalos são preenchidos da mesma forma, ou seja, usando as médias aritmética e harmônica.

Platão, que não prescinde do rigor matemático, principalmente ao descrever a alma do universo, revela também no discurso de Timeu a presença de uma proporção que os pitagóricos de certa forma sempre procuraram não explicitar. Trata-se dos intervalos que completam os tetracordes, ou seja o "meio tom" existente entre mi e fá e entre si e dó. Este valor é dado por 256/243, bem menor que o "meio tom" da escala pitagórica, e que era chamado de "diésis" que significa " uma passagem", ou "leimma" que significa "o que resta". Estas denominações indicam claramente que esses intervalos eram desconsiderados, deixados para um segundo plano. Para completar as relações matemáticas deve ser notado que 81/64 (Mi) e 243/128 (Si) quando multiplicados por 256/ 243 dão 4/3 (Fá) e 2 (Dó).

Na continuação deste trecho do diálogo diz Timeu que "[...] desse modo, o todo do qual ele (o Demiurgo) estivera separando essas partes tornou-se finalmente consumido por completo". E mais adiante "[...] e a alma, girando sobre si mesma, deu início divino a uma vida incessante e inteligente por toda a duração do tempo. E assim ele criou, por um lado, o corpo visível do céu, por outro, a própria alma, certamente invisível, participando da razão e da harmonia, nascida sob o melhor entre (as coisas) inteligíveis e eternas, sendo a melhor das coisas que foram geradas. 


\section{HUMANAS}

A percepção da música como um instrumento divino no pensamento pitagórico, elevado a seu mais alto nível no Timeu de Platão é, a nosso ver, o elemento mais forte do "logos" 48 que preside a manutenção da escala diatônica pitagórica por tantos séculos. Sua estrutura básica é mantida até os nossos dias e foi respeitada mesmo por aqueles que, no passado, discordavam da aplicação rígida das regras matemáticas a outros intervalos que não fossem os de oitava, quarta e quinta, as consonâncias consideradas naturais.

O temperamento igual, fundamental para o enriquecimento da arte musical, manteve intacta a perfeição da oitava na relação $2: 1^{49}$ e alterou em valores mínimos as relações matemáticas da quinta e da quarta ${ }^{50}$. Os demais intervalos foram temperados em proporções bastante superiores, notadamente a terça ${ }^{51}$.

E assim, como proposta de conclusão, pode-se sugerir que existiu na Grécia Antiga um notável conjunto de fatores e circunstâncias que, se por um lado permitiu o estabelecimento de uma extraordinária teoria musical, por outro, exatamente pela força da sacralidade de sua origem e do pensamento filosófico, manteve os ouvidos humanos presos, por muitos séculos, à maravilhosa perfeição da oitava e à dissonância da terça que só os temperamentos iniciados no Renascimento vieram aplacar.

\section{Anexo I}

Filolau de Crotona Fragmento $n^{\circ} 6^{52}$ - parte final (tradução do autor)

A magnitude da oitava (harmonia) é a quarta e a quinta. A quinta é maior que a quarta por um tom inteiro. Da "hypata"até a "mesa" existe a quarta, da "mesa" até a"neata"(existe) a quinta, da "neata"para a "trita" a quarta, da "trita" para a "hypata" a quinta; entre a "mesa" e a "trita" há um tom inteiro; a quarta é quatro terços (4/3) a quinta é três meios (3/2) e a oitava é o dobro (2/ 1), portanto a oitava ( harmonia) é (composta de ) cinco tons inteiros e um semitom, a quinta é três tons inteiros e um semitom e a quarta é dois tons inteiros e um semitom.

\footnotetext{
${ }^{48}$ Logos tomado no sentido de pensamento, razão.

${ }^{49}$ A oitava também era chamada pelos gregos de uma "harmonia".

${ }^{50} \mathrm{O}$ valor da quinta no temperamento igual é de 1,4983 (em vez de 1,5) e o da quarta é de 1,3348 (em vez de 1,3333). São diferenças expressas na terceira casa decimal, portanto muito pequenas.

${ }^{51} \mathrm{O}$ valor da terça no temperamento igual é de 1,1225 , inferior a 1,2500 da terça natural e bem menor que a terça pitagórica cujo valor é 1,2656. São diferenças já na segunda casa decimal, altamente perceptíveis pelo ouvido humano.

${ }^{52}$ Fonte: Diels, Hermann (Die Fragmente der Vorsokratiker, Weidman 1951).
} 


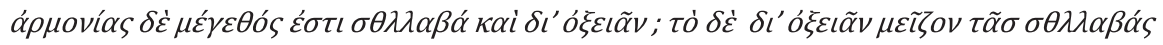

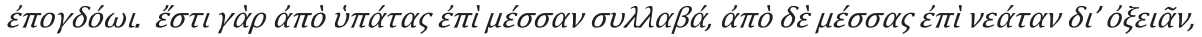

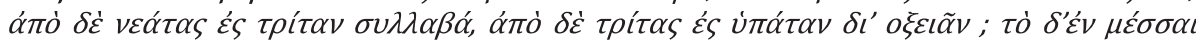

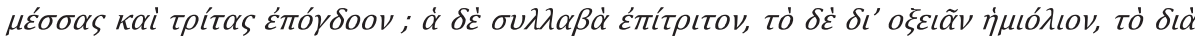

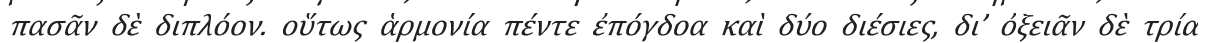

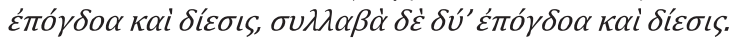

Para um melhor entendimento deste trecho registram-se abaixo os nomes das notas musicais mencionadas.

\begin{tabular}{|c|c|c|c|}
\hline Dial. Ático & Dial. Dórico & Transliteração & $\begin{array}{l}\text { Nome atual } \\
\text { (modo dórico) }\end{array}$ \\
\hline ùnó $\tau \varepsilon$ & ن̀ாó $\tau \alpha$ & hypata & $\mathrm{Mi}$ \\
\hline$\mu \varepsilon \varepsilon^{\prime} \sigma \varepsilon$ & $\mu \varepsilon \varepsilon^{\prime} \sigma \alpha$ & mesa & $\mathrm{La}$ \\
\hline$\tau \rho i ́ \tau \varepsilon$ & $\tau \rho i ́ \tau \alpha$ & trita & $\mathrm{Si}$ \\
\hline 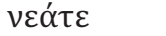 & 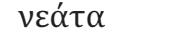 & neata & $\mathrm{Mi}^{1}$ \\
\hline
\end{tabular}

Filolau usa a palavra "trita" para designar a quinta nota da escala. Esta é uma denominação antiga que se refere á escala de 7 tons. Na escala de 8 tons a quinta nota passou a se chamar "paramesa". A sexta nota passou a "trita", a sétima nota a "paraneata" e a oitava a "neata". É também importante registrar

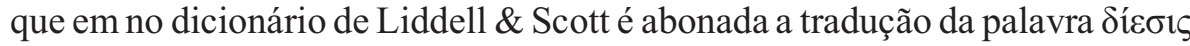

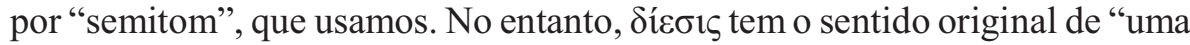
passagem" e para Aristoxeno significa "todo intervalo menor do que um semitom". Este intervalo, também é chamado por Nicômaco de Gerasa pela palavra $\lambda \varepsilon i ́ \mu \mu \alpha$ que significa "o que resta", o que mostra a dificuldade dos teóricos gregos em tratar de um assunto que apenas Platão esclareceu matematicamente em seu diálogo Timeu como mostramos no item 10 deste trabalho.

\section{Anexo II}

Fragmento $n^{\circ} 51$ de Heráclito e Versos 130 e 131 do Hino Homérico a Apolo $^{53}$ (Traduções do autor)

Fragmento $n^{\circ} 51$

Eles não compreendem como o que difere concorda consigo mesmo: harmonia de tensões contrárias exatamente como a do arco e a da lira.

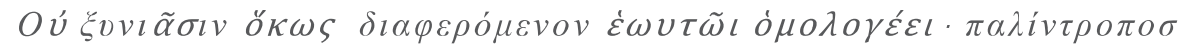

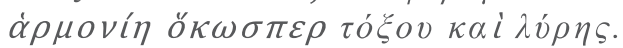

${ }^{53}$ Fontes: H. Diels (Die Fragmente der Vorsokratiker, Weidman 1951) e L.A.M. Cabral (O hino Homérico a Apolo, Unicamp 2004 Ed. Bilingue). 
Um primeiro fato interessante neste fragmento é observar o número de palavras usadas pelo filósofo. A tradução acima usa 23 palavras enquanto a inglesa de K. Freemann usa 26 e a alemã de Diels usa 23. Heráclito usou apenas 12, dividindo a frase (pelos dois pontos, em grego antigo apenas um ponto) em duas partes com 6 palavras cada. Ritmo e simetria. Harmonia de duas frases que fundem um pensamento. Neste fragmento fica explícita a teoria Heraclitiana da unidade que existe no mundo, formada pela combinação dos opostos. Sua crença na guerra (pólemos) como elemento universal e no conflito (éris) como sede da Justiça (díke), está ligada a esta teoria ${ }^{54}$ pois, no conflito os opostos são combinados e produzem o movimento que leva à harmonia. A ligação que se mostra eloqüente é a do arco com a lira. Talvez a mais sagrada união destes dois instrumentos seja sua aparição conjunta no ato do nascimento de Apolo, o deus das artes, da claridade e da razão e, ao mesmo tempo, o magnífico e terrível asseteador, protagonista importantíssimo da guerra de Tróia, onde homens, heróis e deuses participavam, lado a lado, de batalhas sangrentas. Este registro está no Hino Homérico a Apolo onde o poeta, ao descrever o parto de Leto, diz às linhas 130 e 131:

\section{Hino Homérico a Apolo - Versos 130 e 131}

Imediatamente Apolo Febo aos imortais proclamou:

Existam para mim a amada lira e o recurvo arco,

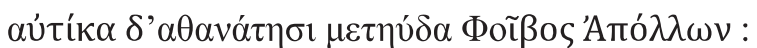

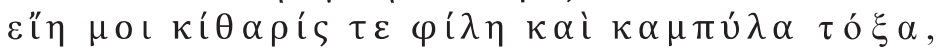

$\mathrm{O}$ arco e a lira só existem, na realidade, quando submetidos às tensões opostas das forças que retesam e impulsionam, que oprimem e libertam. Qual das forças, senão as duas, em harmonia, produzem o movimento da flexa e das ondas sonoras? A harmonia que rege a ação, tanto do arco como a da lira, se manifesta no movimento: impulsão e vibração. E está nesta harmonia das forças contrárias, no movimento, o elo de ligação com o conceito de impermanência ${ }^{55}$.

\section{Referências bibliográficas}

BARKER, A. Greek nusical writings I. Cambridge: Cambridge University Press, 2004.

\footnotetext{
$\overline{54}$ Explicitada, entre outros, no fragmento $\mathrm{n}^{\mathrm{o}} 80$

${ }^{55}$ Conceito tratado em vários outros fragmentos, sendo os mais conhecidos aqueles que se referem aos rios.
} 
BARNES, J. Bach's keyboard temperament, Early Music, 1979.

BORNHEIM, G.A. (Org.). Os filósofos pré-socráticos. São Paulo: Cultrix.

BRANDÃO, J.S. Mitologia grega, vol. I, II, III. Petrópolis: Editora Vozes, $3^{\text {a }}$ Ed., 1987.

CABRAL, L.A.M. O hino homérico a Apolo. Campinas: Unicamp, 2004.

CRISCHLOW, K. The Platonic tradition on the nature of proportion - In homage to Pythagoras. Lindisfarne Books, 1994.

DIELS, H. Die fragmente der Vorsokratiker, Ed. Weidmann, 6ª Edição, 2004

FREEMANN, K. Ancilla to the pre-Socratic philosophers. Harvard University Press, Cambridge, 24a ed., 1966.

GODWIN, J. The harmony of the spheres, inner traditions. Int., Rochester, Vermont 1993

GUTHRIE, K.S. The Pythagorean sourcebook and library. Phanes Press, Grand Rapids, Mich. 1988.

HeLMholtZ, H. On the Sensations of Tone. Dover Publications, New York, 1954.

IAMBLICO. Life of Pythagoras. Tradução: Thomas Taylor. Inner Traditions Institute Rochester, Vermont, US Edition 1986.

JEANS, J. Science and music. Dover Publications, New York, 1968.

JOWETT, B. The dialogues of Plato. Encyclopaedia Brittanica Inc. 1952.

KAHN, C.H. Pythagoras and the Pythagoreans. Hackett Publishing. Indianapolis Cambridge, 2001.

MACRAN, H.S. The harmonics of Aristoxenus. Ed. Bilingue, Oxford Clarendon Press, 1902.

McCLAIN, E.G. The Pythagorean Plato. Nicolas-Hays, Inc. York Beach Maine 1984.

MONRO, D.B. The modes of ancient Greek music. Oxford Clarendon Press, 1894.

MOUTSOPOULOS, E. La Musique dans l'oeuvre de Platon. Presses Univers. de France, 1959. 


\section{HUMANAS}

PLATÃO, Timée - Les Belles Lettres. Paris Edição bilingue.

NICÕMACO de GERASA. The manual of Harmonics. Trad: Flora R. Levin, Phane Press, Grand Rapids 1994.

RUSSEL, B. History of western Philosophy. Londres: The Folio Society, $6^{\mathrm{a}}$ Ed., 2008.

SERRA, O. Hino Homérico a Hermes. Ed. Bilíngüe, Coleção Koúros, 2006.

SIMONSEN, M.H. Ensaios analíticos. Rio de Janeiro: FGV, $3^{\text {a }}$ Ed., 1998.

WEST, M. L. Ancient greek music. Oxford Clarendon Press, 1992, Rep. 2005.

THOMAS, I. Greek Mathematics I. Harvard University Press Cambridge, Ed. Bilingue, 2002. 